\title{
The effect of Acceptance and Commitment Therapy on the reduction of anxious thoughts in students
}

\author{
Peyman Dousti $^{1}$, Hossain Mohagheghi ${ }^{2}$, Davood Jafari ${ }^{3}$ \\ Received:20.08.2015 \\ Revised:25.09.2015 \\ Accepted: 30.09.2015
}

\begin{abstract}
The aim of the present study is to investigate the effect of Acceptance and Commitment Therapy on the reduction of anxious thoughts in Islamic Azad University Students of Hamadan. The study is a quasi-experimental research with a pretest-posttest control group design. The population of the study was all Islamic Azad University students of Hamadan $(\mathrm{N}=15000)$. The sample of the study consisted of 30 undergraduate students (20 females and 10 males) from the mentioned population. To sample was selected from the candidates who received the highest scores in a test of anxious thoughts by Wells, and then was randomly divided into control and experimental groups. This instruments used was Wells' anxiety though scale. This instrument measures three scales of social anxiety, generalized anxiety, and health anxiety. Acceptance and Commitment Therapy protocol was conducted through 8 treatment sessions and one-month control session. The results indicated that Acceptance and Commitment Therapy reduces anxious thoughts $\mathbf{p}<0.05$ ).
\end{abstract}

Key words: Acceptance and Commitment Therapy, Anxious thoughts, generalized anxiety disorder, social Phobia, health anxiety.

\section{Introduction}

All individuals are sometimes distressed; tests, sport competitions, a meeting with an important person, and concerns about the new relationship can all cause feelings of anxiety. Think about your own experiences in which there was anxiety. Although all these experiences are sad, none of them is considered an abnormal performance. People with anxiety disorders would become helpless by the chronic and acute feelings of anxiety (Haljin \& Vitborn, 2014, Translated by Seyyed Mohammadi, 2015). The concept of anxious thoughts was proposed by Wells (1994) in three scales of social anxiety disorder, physical anxiety disorder, and generalized anxiety disorder (Bahrami \& Rezvan, 2007).

Some people feel anxious in social situations. In acute cases, this anxiety would turn into social anxiety disorder whose distinguishable symptoms include: severe and persistent fear of social or performance situations, which may lead to embarrassment. The individual realizes their irrational fear, and in such cases they avoid such situations, and ultimately, this anxiety disrupts the individual's performance and social relationships (American Psychiatric Association, 2013). Some people constantly have concerns about their health conditions. They regularly check and monitor their own bodies. They constantly check their vital signs and have extreme concerns regarding their health

\footnotetext{
Author's Address

${ }^{1}$ Hamedan Branch, Islamic Azad University, Hamedan, Iran.

${ }^{2}$ University of Bu-Ali Sina of Hamedan, Iran

${ }^{3}$ Malayer Branch, Islamic Azad University, Malayer, Iran

Email: peyman@dousti.net
}

conditions. If such concerns last for more than six months, health anxiety can be identified for such individual (Abramowitz and \& Braddock, 2011). In people with anxiety disorders, concern is a process that can change into some strategies to uncover and deal with threatening dangers (Hazlett-Stevens, 2010).

Generalized Anxiety Disorder causes a more extreme and extended concern, which is regarded as the main disturbing feature of this disorder. People with Generalized Anxiety Disorder have negative beliefs about anxiety (such as believing that anxiety is uncontrollable and dangerous) (Bahrami and Rezvan, 2007). Anxiety is an unpleasant and vague feeling of fear and concern of unknown origin that a person experiences, and it includes uncertainty, helplessness and physiological arousal (Sheikh Mohammadi et al., 2011). The outbreak of generalized anxiety disorder is between 1 to 3 percent, with a 2 to 1 female to male ratio. Also, the outbreak of social anxiety is 7 percent, which is more prevalent among children, teenagers and women. The outbreak of Health anxiety disorder is reported to be 4 to 6 percent, and ratio of catching it, is the same for men and women and its onset is usually between 20 to 30 years of age (Ganji, 2013). Research has indicated that about $21 \%$ of students suffer from anxiety (Ghasemnejad et al., 2010). Anxiety disorders are among the most common disorders, and can lead to impaired academic performance, social adjustment, family life and peer relationships. The excitement has negative emotions, and includes a sense of concern regarding the danger that is likely to happen. 
Anxiety symptoms are almost similar in children and adults, but its manifestations differ at different ages (Sheikh Mohammadi et al.,2011).

Anxiety would become a clinical concern when disrupts the ability to function in everyday life, so that the individual is struck by a maladaptive mode that is characterized by severe mental and physical reactions. People with anxiety disorders are not able to carry out their daily activities. Their anxiety is unpleasant and it makes them incapable of enjoying normal situations. However, in addition to such features, they try to avoid situations that make them feel anxious. They lose opportunities for enjoyment or baheving based on their desire (Haljin and Vitborn, 2014: Translated by Seyyed Mohammad, 2015). Getting rid of mental illnesses is the first step to human development and health, and humans have a long way ahead after going through this step (Parcham \& Ghoveh Oud, 2010). In this full-time approach, we are dealing with psychological flexibility. By the integration of acceptance intervention and mindfulness in the strategies of commitment and change, this treatment helps patients to achieve a happy, purposeful, and meaningful life (Flexman et al., 2011: Translated by Mirzaee and Nonahal, 2015). Acceptance and Commitment Therapy is different with cognitive behavioral therapy. Its underlying principles include: 1) acceptance or willingness to experience pain or other disturbing events without attempting to control them 2) value-based action or commitment coupled with a tendency to act as meaningful personal goals prior to the removal of unwanted experiences. Language methods and cognitive processes interact with other non-verbal dependencies, leading to healthy functioning. This method involves exercises based on confrontation, language metaphors and methods such as mental health care (Vallis et al., 2003). The ultimate goal of this model is increasing the frequency of living worthwhile. The underlying assumption of Acceptance and Commitment Therapy is that a substantial portion of psychological distress is a normal part of human experience (Hayes et al., 2012).

The change is done indirectly in this method. Unlike cognitive-behavioral therapy that directly focuses on changing thoughts and feelings, Acceptance and Commitment Therapy does not change the thoughts and feelings, but lead people to accept, be aware of, and observe themselves (Hayes et al., 2012). Acceptance and Commitment Therapy help people to experience problematic thoughts and emotions in a different way, rather than systematically trying to change or decrease their frequencies (Linehan,2014). In this treatment, it is taught to the patient that any action to prevent or control unwanted mental experiences (thoughts and feelings) is ineffective or counter-effective and will exacerbate their impact; therefore, they must fully accepted these experiences without any internal or external reaction to remove them (Forman and Herbeit, 2008).

Anxiety disorders are often treated through cognitive-behavioral therapies. But many of the patients have not benefitted from this therapy or have experienced little improvement. Consequently, specialists and researchers were drawn to other approaches. Among such new approaches, mindfulness-based therapy and interventions based on acceptance and commitment can be mentioned (McKenzie and Kocovski, 2010).

A large array of research, so far, has confirmed the worldwide interest in behavior change model in the view of the theoretical model of Relational Frame Theory and acceptance and commitment therapy. Among these studies, Swain et al, (2013) on depression and anxiety, Twohig et al. (2011) on OCD, Moran and Consulting (2010) on managers flexibility, Veiga-Martinez et al (2007) on auditory hallucinations, Pankey and Hayes (2003) on psychosis, Dousti (2015) on depression, Izadi et al (1392, 1393) on symptoms of compulsive obsessive disorder, Mehrdoust et al (2013) on reducing attention to focus on self and selfefficiency beliefs, Hosinaiee et al. (2013) on stress and job burnout, and Rajabi et al (2013) on the symptoms of anxiety and marital conflict can be mentioned. The researcher's study suggests that the present study is the first research which investigates the effect of Acceptance and Commitment Therapy on anxious thoughts.

\section{Materials and Method}

The present study is an empirical, quasiexperimental research with a pretest - posttest control group design, which is aimed to investigate the effect of on Acceptance and Commitment Therapy on reducing the anxious thoughts. The population included all students of Azad University of Hamedan $(\mathrm{N}=15000)$. The sample of the study consisted of 30 students ( 20 females and 10 males) from the mentioned community. A total number of 400 questionnaires were distributed among the students. The sample was selected from the candidates who received the highest scores in a test of anxious thoughts by Wells, and then was 
randomly divided into control and experimental groups. The experimental group participated in eight 45-minute sessions individually for the treatment, while the control group received no treatment. A month after the implementation of the 8 sessions based on Acceptance and Commitment Therapy, a posttest was given to both groups. All sessions had a stable pattern: examining the response to the previous session, examining the assignments, the subject related to that specific session, and the assignment of homework regarding the presented material and in accordance with the central processes of acceptance and commitment therapy.

The instrument used in this study, is the questionnaire of anxious thoughts by Wells. This instrument contains 22 items, and its purpose is to assess anxious thoughts. The components of the questionnaire include social anxiety, Health anxiety and generalizable anxiety. The validity of the questionnaire of anxious thoughts was examined through correlation methods. Cronbach's alpha reliability coefficient of the questionnaire was also 91\% (Fati et al., 2010). Data analysis was done by SPSS software V.22. To determine the normality of distribution of data, the Kolmogorov Smirnov test was used, and in order to determine the equality of variances the Levene test was utilized. In these statistical tests, $p>0.05$ was considered to be the significance level. Then, descriptive statistics was used to determine mean, variance and standard deviation of the data. In inferential statistics, in order to analyze the collected data, the analysis of covariance for independent groups was used.

Ethical considerations were also made. Some explanations were given to participants about the research project, and they were assured that the results would remain confidential. The content of the therapy sessions is as follows:

\begin{tabular}{|c|c|}
\hline \multicolumn{2}{|r|}{ Summary of the Sessions } \\
\hline The first session & $\begin{array}{l}\text { Getting details of the patient's problem, the measurement of primary values } \\
\text { using the metaphor of grave and magic wand, constructive hopelessness, and } \\
\text { practicing mindfulness by eating snacks. }\end{array}$ \\
\hline The second session & $\begin{array}{l}\text { Mindfulness meditation practice was done by the patient. The patient became } \\
\text { aware of the relationship between his/her internal conflict and its } \\
\text { ineffectiveness using the lie detector metaphor. The patient, using the } \\
\text { emotions that previously was avoiding, made a non-defensive contact with } \\
\text { the metaphor of the polar bear and dunes. }\end{array}$ \\
\hline The third session & $\begin{array}{l}\text { Mindfulness was practiced. Using the metaphor of bus passengers, the } \\
\text { patient was shown that he/she cannot move towards the values and } \\
\text { simultaneously fight with intruding thoughts. By practicing the verbose } \\
\text { mind, it was shown that thoughts have no control over us. The practice of } \\
\text { milk, milk, milk was used to temporarily remove the meanings of words } \\
\text { from each other. }\end{array}$ \\
\hline The fourth session & $\begin{array}{l}\text { Mindfulness was practiced. With the practice of hard cover and try not to } \\
\text { think of a particular issue, it was shown to the patient that the more they try } \\
\text { to escape from their thoughts, the more force the thoughts gain to stay. The } \\
\text { practice of objectifying the content of thoughts to imagine yourself was } \\
\text { given to the patient. The practice of tug of war with a monster was done to } \\
\text { free the thoughts. }\end{array}$ \\
\hline The fifth session & $\begin{array}{l}\text { Mindfulness was practiced. Also, the patient did some practices to stay with } \\
\text { problematic excitement. The practice of read your thoughts content with } \\
\text { nursery songs was done by the patient for cognitive DeFusion. Questions } \\
\text { were asked regarding the objectives of the patient in order to move towards } \\
\text { the values and to make him/her understand that the ultimate goal of helping } \\
\text { him/her is to make a meaningful and more enthusiastic life. }\end{array}$ \\
\hline The Sixth session & $\begin{array}{l}\text { Mindfulness exercises were done. The patient's objectives were determined. } \\
\text { The patient specified the importance of his/her values and examined the } \\
\text { alignment of his current behavior for his values. Planning was done by the } \\
\text { patient to do activities to achieve the objectives. }\end{array}$ \\
\hline The seventh session & Mindfulness self-observing exercises were done. The patient was prepared to \\
\hline
\end{tabular}




\begin{tabular}{|l|l|}
\hline & $\begin{array}{l}\text { confront the likely internal and external obstacles to reach his goals. The } \\
\text { message that the quality of the committed acts is more important than its } \\
\text { quantity, was given to the patient. }\end{array}$ \\
\hline The Eighth session & $\begin{array}{l}\text { After the mindfulness practices, the previous sessions' practices were } \\
\text { reviewed, and the patient was ready to finalize the treatment period }\end{array}$ \\
\hline
\end{tabular}

Table 1-Descriptive indices of Well's anxious thoughts scores in the experimental and control groups

\begin{tabular}{ccccc}
\hline $\begin{array}{c}\text { Standard } \\
\text { Deviation }\end{array}$ & Mean & & Group & Variable \\
\hline 8.77 & 42.26 & Pre-test & experimental & Anxious \\
9.58 & 35.60 & Post-test & & thoughts \\
10.55 & 41.93 & Pre-test & control & \\
10.85 & 42.06 & Post-test & & \\
\hline
\end{tabular}

Table 2-normality of distribution of the data using the Kolmogorov - Smirnov

\begin{tabular}{ccc}
\hline Post-test & Pre-test & \\
\hline 30 & 30 & \\
38.83 & 42.10 & \\
10.58 & 9.53 & \\
0.127 & 0.094 & \\
0.127 & 0.088 & \\
-0.070 & -.094 & \\
0.127 & 0.094 & Statistical test \\
$0.200^{\mathrm{c}, \mathrm{d}}$ & $0.200^{\mathrm{c}, \mathrm{d}}$ & Asymp. Sig. (2- \\
& & tailed) \\
\hline
\end{tabular}

Table 3-Equality of Mean in two independent groups

\begin{tabular}{cccc}
\hline Sig. & F & & \\
\hline 0.331 & 0.987 & Equal variances assumed & Pre-test \\
0.456 & 0.571 & Equal variances assumed & Post-test \\
\hline
\end{tabular}

Table 4- Analysis of covariance of Well's anxious thoughts in both groups

\begin{tabular}{cccccc}
\hline Sig. & F & Mean squares & DF & Sum of squares & Change source \\
& & & & & \\
\hline 0.00 & 590.063 & 2520.553 & 1 & 2520.533 & Pretest \\
0.00 & 63.489 & 271.200 & 1 & 271.200 & $\begin{array}{c}\text { Effect of } \\
\text { method } \\
\end{array}$ \\
& & 4.272 & 27 & 115.334 & $\begin{array}{c}\text { Error } \\
\text { Total }\end{array}$ \\
\hline
\end{tabular}

\section{Results and Discussion}

According to data presented in table 1 , the mean score of anxious thoughts in the experimental group reduced from 42.26 (pretest) to 35.6 (posttest).

To determine the population distribution (normal distribution of data) the Kolmogorov - Smirnov test was used (Table 2); and to determine the equality of variances the Levin test was used (Table 3). In these statistical tests, p> 0.05 was considered to be significant. In order to examine the research question "Does the Acceptance and Commitment Therapy reduce students' anxiety thoughts"?, the analysis of covariance was used, through which the posttest scores of the experimental and control groups were compared, and also their pre-test scores went under statistical control. The findings indicate that on the basis of the obtained anxious thoughts scores, the difference between the two groups in post-test is significant at the 5\% level; therefore, the null hypothesis is rejected. Hence, it 
can be reported that the Acceptance and Commitment Therapy is effective in reducing anxiety thoughts.

\section{Conclusion}

This study aimed to determine the effect of Acceptance and Commitment Therapy on reducing the anxious thoughts among Hamadan Azad University students. As statistical analysis showed, the main hypothesis of this study is confirmed, which claimed that the Acceptance and Commitment Therapy is effective on reducing anxiety thoughts among Azad University students of Hamedan. Among 15 subjects in the experimental group, 13 patients showed favorable changes in Wells' scores of anxious thoughts.

The findings of Swain et al (2013), Rajabi and Yazdkhasti (2013), Rajabi, Imani, Khojaste-Mehr, and Beshlideh (2013), Kaviani et al. (1384), Block and Wulfert (2000), Eifert and Forsyth (2005), and Levitt et al. (2004) are in line with the result of this research regarding the impact of Acceptance and Commitment Therapy on to reducing generalized anxiety; and also with the results of Pourfaraj Omran (2011) on the impact of Acceptance and Commitment Therapy on reducing social anxiety.

To explain these findings in terms of the impact of Acceptance and Commitment Therapy on reducing generalized anxiety and social anxiety, it can be said that, from the standpoint of acceptance and commitment therapy (patients with obsessivecompulsive disorder, anxiety disorders, drug abuse, etc.), they have the same function, as their aim is to avoid the same experience (Wilson and DuFrence, 2009). The aim of the Acceptance and commitment therapy is not the change or frequency of annoying thoughts and feelings, but its main purpose is to strengthen the psychological flexibility (Flexman et al., 2011: Translated by Mirzaee and Nonahal, 2015). It seems that reception, which means dealing with pain on the way to the values, rather than avoidance of experiences, plays a major role in reducing the symptoms of anxiety. Apparently experiential avoidance in the long run, cause more symptoms of anxiety. Moving toward the life values is associated with pains and difficulties the avoidance of which cannot lead to a valuable life. In the Acceptance and Commitment Therapy, acceptance means the desire to deal with the pain and difficulties. Furthermore, the lack of clear values for living can be another reason for the occurrence of symptoms. Value means the deepest desire for something, for which a lot of effort is made. If humans fail to recognize these values, they cannot move towards them. In this approach, one of the assumptions is that the lack of clear value causes damage. The other assumption of this research is that the cognitive DeFusion can reduce the symptoms of anxiety disorder. Assuming the meanings of words a reality also causes the disorder symptoms. When the mind thinks that it knows everything about anxiety, more anxiety reactions will occur. Therefore, separating the meanings words from them and not assuming them to be real help a great deal to reduce the symptoms of anxiety. Also, humans tend to assume emotions and feelings a part of their own. In this approach, it is assumed that, if the individual frees himself from his troublesome feelings, he will greatly contribute to the improvement of illogical anxiety reactions. Commitment means that the individual, despite the pains on the way of his values, is willing to experience them and move a step forward in that direction. Another assumption is that the person should be committed to actions in line with his values. Further, the use of the components of mindfulness and contact with the present moment, instead of sinking into the inner world, can be another reason to reduce the symptoms of anxiety. It is assumed that the no contact with the present moment, and living in the past or future can cause damage to the person. It seems that the implementation of these six processes, which can totally lead to psychological flexibility, reduces anxiety symptoms in subjects of the present study.

\section{Acknowledgments}

We hereby would like to thank all the students who helped us in this study.

\section{References}

Abramowitz, Jonathan S. Braddock, Autumn E. 2011. Hypochondriasis and health anxiety. Hogrefe Publishing.

American Psychiatric Association. 2013. Diagnostic and Statistical Manual of Mental Disorder (Revised 5 ed). Washington: American Psychiatric Association.

Bahrami, F; \& Rezvan, S. 2007. The relationship between anxious thoughts and metacognitive beliefs among high school students suffering generalized anxiety disorder. Iranian Journal of Psychiatry and Clinical Psychology. 13(3). 249-255.

Block J A. Wulfert E. 2000. Acceptance or change: Treating socially anxious college students with ACT or CBT. The Behavior Analyst Today. 1 (2). 1-55. 


\section{Dousti et al.}

Dousti, P 2015. The effect of Acceptance and Commitment Therapy on reducing depression of residence of District 7 of Tehran. International Conference of Psychology and Educational Sciences. Shiraz Kharazmi Institute of Science and Technology.

Eifert, H. G. Forsyth, P. J. 2005. Acceptance \& Commitment Therapy for anxiety disorders. Oakland: harbinger.

Fati, L; Moutabi, F; Moloudi, R; \& Ziaee, K. 2010. Psychometric adequacy of the Persian version of thought control questionnaire, and anxiety thoughts questionnaire in Iranian students. Journal of psychological methods and models. 1, 81-103.

Flexman, P; Blackledge, J.T; \& Bond, F. 2011. Acceptance and commitment therapy: distinctive features. Translated by Mosleh Mirzaee and Saman Nonahal. (2015). Tehran: Arjmand Publications.

Forman, E. M. Herbert, D. 2008. New directions in cognitive behavior therapy: acceptance based therapies, chapter to appear in W. O'donohue, Je. Fisher, (Eds), cognitive behavior therapy: Applying empirically supported treatments in your practice. 2nd ed. Hoboken. NJ: Wiley. 263-26.

Ganji M. 2014. psychopathology based on DSM5. Tehran: Savalan Publications.

Ghasemnezhad, S; Jalalmanesh, S; Rasadi, M; Mahmoudi, M. 2011. Investigating the relationship between anxiety and hypochondriasis in students of Medical Sciences in Islamic Azad University in Lahijan in 1387. Islamic Azad University Journal of Medical Sciences. 21(3), 222-226.

Halijen, R. P; Cross-Vitborn, S. 2014. Psychopathology based on DSM5. Yahya Syed Mohammad. (2015). Ravan publication, Volume 1.

Hayes, S. C. Strosahl, K.D. Wilson, K.G. 2012. Acceptance and Commitment Therapy: The process and practice of mindful change. New York: Guilford Press.

Hazlett-Stevens, H. 2010. Psychological Approaches to Generalized Anxiety Disorder: A Clinician's guide to Assessment and Treatment. New York: Springer.

Hosinaiee, A; Ahadi, H; Fati, L; Heydari, A; \& Mazaheri, M. 2013. Effect of acceptance and commitment group therapy on job stress and burnout. Iranian Journal of Psychiatry and Clinical Psychology. 19(2), 109-120.
Izadi, R; Abedi, M, R. 2013. Reducing obsessivecompulsive symptoms in patients with treatmentresistant thought and action obsessive-compulsion through the acceptance and commitment-based therapy. Scientific Journal of Feiz. Volume 17 (3), 275-286.

Izadi, R; Neshat-doost, H; Asgari, K; Abedi, M. 2014. Comparison of acceptance and commitment-based therapy and cognitive-behavioral therapy on patients with obsessive-compulsive symptoms. Behavioral Sciences Research. 12 (1), 19-33.

Kaviani, H; Javaheri, F; Bahiraee, H. 2005. The effectiveness of mindfulness-based cognitive therapy in reducing the negative automatic thoughts, dysfunctional attitude, depression and anxiety. New cognitive science. 7(1), 49-59.

Levitt, J. T. Brown, T. A. Orsillo, S. M. Barlow, D. H. 2004. The effects versus suppression of emotion on subjective and psychological response to carbon dioxide challenge in patients with panic disorder. behavior therapy. 35. 747-766.

Linehan, M. 2014. cognitive-Behavioral treatment of Borderline personality Disorder. New York : Guilford Press.

MacKenzie, Meagan B. Kocovski, Nancy L. 2010. SelfReported Acceptance of Social Anxiety Symptoms: Development and Validation of the Social AnxietyAcceptance and Action Questionnaire. International Journal of Behavioral Consultation and Therapy. 6(3): 214-232.

Mehrdoust, Z; TaherNeshat-Doust, H; Abedi, A. 2012. The effectiveness of acceptance and commitment therapy on the reduction of focused attention on self, and improvement of social self-efficacy beliefs. Psychological Methods and Models. 3(11), 67-82.

Moran, Daniel J. Consulting, Pickslyde. 2010 . Using Acceptance and Commitment Training to Develop Crisis-Resilient Change Managers. IJBCT . 6(4): 341-355.

Parcham, A; \& Ghove Oud, M. 2010. Mental health from the perspective of Islam and psychology. Minhaj. 6(11), 49-77.

Porfaraj-Omran, M. 2011. Acceptance and commitment group therapy effectiveness on students' social phobia. Knowledge \& Health Quarterly. 6(2), 1-5.

Pankey, Julieann. Hayes, Steven C. 2003. Acceptance and Commitment Therapy for Psychosis. International Journal of Psychology and Psychological Therapy. 3(2) : 311-328. 


\section{The effect of Acceptance and Commitment}

Rajabi, S; \& Yazdkhasti, F. 2013. Acceptance and commitment-based group therapy efficacy on womens' anxiety and depression suffering from MS disease. Journal of Clinical Psychology. 6(1), 29-38.

Rajabi, G; Imani, M; Khojaste-Mehr, R; \& Beshlideh, K. 2012. Effectiveness of acceptance and commitmentbased therapy, and integrated behavioral couple therapy on women's' anxiety and marital compatibility with marital chaos and generalized anxiety disorder. Journal of Behavioral Sciences. 11(6), 600-619.

Roemer, L. Orsillo, S. M. Salters-Pedneault, K. 2008. Efficacy of an acceptance-based behavior therapy for generalized anxiety disorder:evaluation in a randomized controlled trial. Journal of Consulting and Clinical Psychology. 76. 1083.1089.

Sheikh-Mohammadi, R; Asli-Azad, M; Arefi, M; \& Farhadi, T. 2011. The effectiveness of children-based play therapy on depression and anxiety of girls suffering from depression and anxiety disorder in primary school. Psychological methods and models. 2, 90-71.

Swain, Jessica. Hancock, Karen. Dixon, Angela. Koo, Siew. Bowman, Jenny. 2013. Acceptance and Commitment Therapy for anxious children and adolescents: study protocol for a randomized controlled trial. .(Retrieved 18 OCT 2015, from http://www.ncbi.nlm.nih.gov/ pmc/articles/PMC3662565).
Twohig, Michael P. Whittal, Maureen L. Cox , Jared M. Gunter, Raymond 2011. An initial investigation into the processes of change in ACT, CT, and ERP for OCD. IJBCT. 6(1): 67-83.

Vallis, M. Ruggiero, L. Greene, G. Jones, H. Zinnman, B. Rossi, R. Edwards, L. Rossi, J. Prochaska, L. 2003. Stages of change for healthy eating in diabetes: Relationships to Dejographic, eating related, health care utilization and psychosocial factors. Diabetes Care. 2626 (5), 1468-74.

Veiga-Martínez, Carlos. Pérez-Álvarez, Marino. GarcíaMontes, José M. 2007. Acceptance and Commitment Therapy Applied to Treatment of Auditory Hallucinations. Clinical Case Studies. 7(2) : 118-135.

Wells, A. Davies, M.I. 2015. The Thought Control Questionnaire:A measure of individual differences in the control of unwanted thoughts. Behaviour Research and Therapy, 32, 871-878.

Wilson, K, G. DuFrence, T. 2009. Mindfulness for two: an Acceptance and Commitment Therapy Approach to Mindfulness in Psychotherapy. Oakland, CA: New Harbinger. 